\title{
The Phytochemical Analysis and Synergistic Antifungal Effect of Etlingera elatior Jack. Flowers and Murraya koenigii Spreng. Leaves against Candida albican
}

\author{
Zulhabri Othman ${ }^{1,3 *}$ (D) Fasehah Ali $^{2}$ and Asdren Zajmi \\ ${ }^{1}$ Postgraduate Centre, Management and Science University, Seksyen 13, 40100 Shah Alam, Selangor Malaysia. \\ ${ }^{2}$ Faculty of Health and Life Sciences, Management and Science University, Seksyen 13, 40100 Shah Alam, \\ Selangor, Malaysia. \\ ${ }^{3}$ International Centre for Halal Studies, Management and Science University, Seksyen 13, 40100 Shah Alam, \\ Malaysia.
}

\begin{abstract}
Traditional medicinal plant possessed antimicrobial properties. Candidiasis is an infection of Candida albicans which has developed resistance towards antifungal drugs. The extracts of Murraya koenigii Spreng leaves and Etlingera elatior Jack flowers were used as antifungal agents individually and in combination against $\boldsymbol{C}$. albicans. Both extracts were tested for the presence of phytochemicals (alkaloids, tannins, flavonoids, glycosides and saponins). Individual extracts were examined for antifungal activity using Kirby-Bauer test. The minimum inhibitory concentration (MIC) and the minimum fungicidal concentration (MFC) were evaluated using microdilution broth assay and checkerboard assay. The extracts of both plants were positive for the presence of phytochemicals flavonoids, alkaloids, tannins, glycosides and saponins. The inhibition zone of $M$. koenigii leaf and $E$. elatior flower extracts were 8.33 $\mathrm{mm}$ and $8.17 \mathrm{~mm}$ respectively. The MIC of $M$. koenigii and $E$. elatior ranged from $200 \mathrm{mg} / \mathrm{mL}$ to 400 $\mathrm{mg} / \mathrm{mL}$ and in combination, the extracts were indifferent towards $C$. albicans ( $F I C=1.0$ ). MFC revealed there was no visible growth of $C$. albicans on SDA plate. M. koenigii and $E$. elatior have potential to be used individually or in combination as antifungal agents against $C$. albicans.
\end{abstract}

Keywords: Antifungal, Candida albicans, Etlingera elatior, Murraya koenigii, synergistic

\footnotetext{
*Correspondence: zulhabri_othman@msu.edu.my; +603-5521 6809
}

(Received: January 15, 2020; accepted: August 12, 2020)

Citation: Othman Z, Ali F, Zajmi A. The Phytochemical Analysis and Synergistic Antifungal Effect of Etlingera elatior Jack. Flowers and Murraya koenigii Spreng. Leaves against Candida albican. J Pure Appl Microbiol. 2020;14(3):1809-1816. doi: 10.22207/ JPAM.14.3.19

(C) The Author(s) 2020. Open Access. This article is distributed under the terms of the Creative Commons Attribution 4.0 International License which permits unrestricted use, sharing, distribution, and reproduction in any medium, provided you give appropriate credit to the original author(s) and the source, provide a link to the Creative Commons license, and indicate if changes were made. 


\section{INTRODUCTION}

Traditional herbal medicine is a common practice in various human cultures in the world including in Malaysia. The major component of this practice is the usage of medicinal plants, which the leaves are the most common part of a plant that is used in preparing herbal medicine ${ }^{1,2}$. As for lately, this practice has been gaining a significant amount of attention globally ${ }^{3}$. Over the past three decades, about $80 \%$ of the world's population have practice the traditional medicine for their main healthcare ${ }^{4}$.

Plant phytochemicals are bioactive compounds that include essential oils, oleoresin, alkaloids, flavonoids, glycosides, phenolic compounds ${ }^{5,6}$. It can exist in the extracts, ground and dried herbs, or phytochemical substance 7 . The properties are then further exploited in many commercialized products ranging from supplements, pharmaceuticals, antiseptic to dental root canal sealers ${ }^{8}$.

In this study, the extracts of Etlingera elatior Jack. flowers and Murraya koenigii Linn. leaves were used as antifungal against the Candida albicans. E. elatior are from Zingiberacea family and they are tall plants that may reach $6 \mathrm{~m}$ in height ${ }^{9}$. The varying shades of pink and red colours of the petals make Etlingera species very attractive plants. These plants contain phytochemicals such as tannins that are responsible for the antifungal properties. Meanwhile, Murraya koenigii or commonly known as 'daun kari' by the locals belong to the family of Rutacea. It is usually used in various food preparation as a natural flavouring agent among the Malays and Indians ${ }^{10}$. M. koenigii also possessed phytochemicals that have antifungal properties. Since both of these plants possess antimicrobial properties, a synergy between them may produce a greater inhibitory effect. Production of antifungal products from these two plants can give benefits to patients suffering from Candidiasis caused by $C$. albicans.

\section{MATERIALS AND METHODS \\ Plant materials}

Etlingera elatior Jack. and Murraya koenigii Spreng. extracts were used to investigate their synergistic antifungal effects. The parts of the flowers and leaves were used for $E$. elatior and $M$. koenigii respectively. E. elatior and $M$. koenigii was collected from Pernu, Melaka and Sungai Udang,
Melaka respectively. Identification of both plant species of were performed in Universiti Putra Malaysia (UPM).

\section{Preparation of plant materials}

Fresh samples of Etlingera elatior Jack. flower and Murraya koenigii Spreng. leaves were washed with distilled water and cutted into small pieces. The sliced samples were dried in the oven for 48 hours at $40-50^{\circ} \mathrm{C}$ and later kept for further use $^{10}$.

\section{Extraction of plant materials}

The dried samples of $E$. elatior and $M$. koenigii were grind to form powder by using a blender. The extraction was performed using with methanol and ethanol as solvent. About $100 \mathrm{~g}$ of powder for each plant was extracted with $1 \mathrm{~L}$ of $80 \%$ methanol and $95 \%$ ethanol in a separate conical flask for 72 hours. The extracts then filtered through Whatman's filter paper (No. 1) in a filter funnel and followed by evaporation by using a rotary evaporator at $50^{\circ} \mathrm{C}$ for 5 hours. The crude extracts were then collected and weighed using a weighing balance. Afterwards, the collected extracts were placed into a sterile container and labelled prior to being kept at $-20^{\circ} \mathrm{C}$ before analysed $^{10}$.

Determination of percentage yield of the extracts

The percentage yield of the extracts were determined based on the weight of the extract obtained and dried material used as previously described formula ${ }^{11}$.

\section{Phytochemical testing}

\section{Detection of alkaloids}

The Wagner's Test was used to determine the presence of alkaloids. Briefly, the extract (1 $\mathrm{mL}$ ) was added to Wagner's reagent $(1 \mathrm{~mL})$, the reagent was prepared by mixing of iodine $(2 \mathrm{~g})$ and potassium iodide $(6 \mathrm{~g})$ in distilled water (100 $\mathrm{mL}$ ). The presence of alkaloids were identified by the formation of reddish brown precipitate ${ }^{12}$.

\section{Detection of tannins}

The presence of tannins was tested by adding a few drops of $1 \%$ ferric chloride solution to $5 \mathrm{~mL}$ of plant extract. The presence of tannins were indicated by the formation of the green colour precipitate ${ }^{13}$.

\section{Detection of saponins}

The presence of saponins was determined by applying vigorous shaking to diluted plant extracts $(5 \mathrm{~mL})$ in a test tube. The formation of a 
foamy layer was an indicator of this constituent ${ }^{14}$. Detection of glycosides

The mixture of extract $(2 \mathrm{~mL})$ and $50 \%$ $\mathrm{H}_{2} \mathrm{SO}_{4}(10 \mathrm{~mL})$ in a test tube was incubated in a water bath (15 minutes). The mixture was added with Fehling's solution before boiled. The presence of glycosides in the extracts were indicated by the formation of brick-red precipitate ${ }^{7}$.

\section{Detection of flavonoids}

The extract $(2 \mathrm{~mL})$ was added with a few drops of sodium hydroxide solution in a test tube. After addition of diluted sulphuric acid, the yellow colour that became colourless indicated the presence of flavonoids in the extract ${ }^{7}$.

\section{Antifungal activity}

\section{Chemicals and microbial strains}

SDA (Sabouraud Dextrose Agar), peptone water and Nystatin $(100 \mathrm{mg})$ were purchased from Sigma Aldrich. For antifungal testing, a plate of Candida albicans pure culture were obtained from ATCC.

\section{Preparation of inoculum}

Candida albicans were subcultured and maintained on SDA plates as well as in peptone water. Both agar and liquid inoculum were incubated at $37^{\circ} \mathrm{C}$ overnight stored at $4^{\circ} \mathrm{C}$ under aerobic conditions. The liquid inoculum consisting of $5 \times 10^{5} \mathrm{cfu} / \mathrm{mL}$ was identified by absorbance reading at the wavelength of $625 \mathrm{~nm}^{15}$. The absorbance of $0.08-0.13$ was obtained in order to

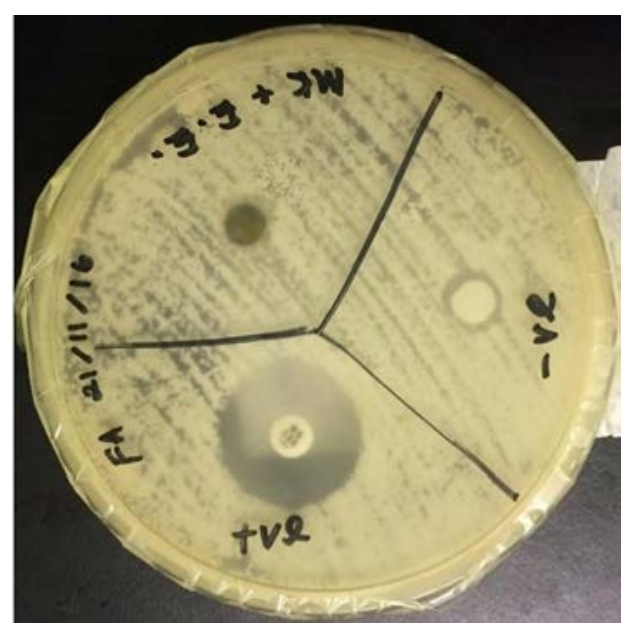

Fig. 1. The diameter $(\mathrm{mm})$ of the zone of inhibition produced by the Etlingera elatior Jack. extracts tested on Candida albicans. meet the turbidity that is similar to $0.5 \mathrm{McF}$ arland standard $^{16}$.

Disc diffusion assay

The method proposed by Bauer et al., (1966) was used to determine the disc diffusion assay of crude extracts yield, with slight modifications ${ }^{17}$. Briefly cotton swabs were dipped into $C$. albicans liquid inoculum spread evenly on the surface of the SDA. About $15 \mu \mathrm{L}$ of the extracts $(400 \mathrm{mg} / \mathrm{mL})$ that were dissolved with DMSO was pipetted onto sterile discs with a diameter of $6 \mathrm{~mm}$. The discs were then placed on the inoculated agar medium. Nystatin and $10 \%$ Dimethyl sulfoxide (DMSO) was used as a positive and negative controls respectively. The agar plates was incubated at $37^{\circ} \mathrm{C}$ for 24 hours. The antifungal activity of each extract was measured by the clear inhibition zone around each disk (Fig. 1).

Determination of the minimum inhibition concentration (MIC)

MIC is described as the lowest concentration of extracts that get rid of the microorganism ${ }^{15}$. It was identified by using the extracts with the strongest antifungal activity from disc diffusion assay. The MIC was done by using micro dilution broth method according to NCCLS (2003) whereby $400 \mathrm{mg}$ of plant extracts was diluted with $1 \mathrm{~mL} 10 \%$ DMSO and pipetted into the first well of a microtiter plate. It was then further diluted up to well 10. Liquid inoculum of $C$. albicans was later introduced to each well on the microtiter plate. Well 11 and 12 served as positive and negative control respectively. The microtiter plate was then incubated for 24 hours at $37^{\circ} \mathrm{C}$.

Determination of the minimum fungicidal concentration (MFC)

The MFC is the lowest concentration that showed either no growth or fewer than three colonies to attain approximately $99.5 \%$ antifungal activity. It was determined based on the result for MIC. After 24 hours of incubation, the last positive wells which has the growth similar to that for negative growth control well, was subcultured onto SDA plates. The inverted plates were incubated at $37^{\circ} \mathrm{C}$.

Fractional inhibitory concentration (FIC) determination

This method was carried out to determine the synergy of the extracts of E. elatior and $M$. 
koenigii against $C$. albicans. The method was similar to MIC, but combining plant extracts on liquid inoculum of $C$. albicans. It is also done on microtiter plate similar to determining MIC of individual plant extracts The result was then calculated by using the formula suggested by Gulam and Bhoj (2015) to determine the Fractional Inhibitory Concentration (FIC) ${ }^{18}$.

\section{Data analysis}

All of the data were collected and analysed using SPSS (Statistical Package for Social Science) version 22.0. The parametric test ANOVA (One Way Analysis of Variance) was used. The difference with a $p$ value $<0.05$ was considered to be statistically significant.

\section{RESULTS}

\section{Percentage of yield of extracts}

Ethanol extracts (95\%) yield a higher percentage for both plants with $12.5 \%$ and $11.8 \%$ for $E$. elatior and $M$. koenigii respectively. In comparison, when extracted using $80 \%$ methanol, the extracts only yield $5.8 \%$ and $5.2 \%$ for E. elatior and $M$. koenigi respectively (Table 1 ).

\section{Phytochemical analysis}

Preliminary phytochemical testing was performed to identify the phytochemical constituents present in both Etlingera elatior Jack. flowers and Murraya koenigii Spreng.leaves. The phytochemicals that present in E. elatior in $80 \%$ methanol is alkaloids, glycosides and saponins but constituents like flavonoid and tannins were not present. Meanwhile, when E. elatior was extracted with $95 \%$ ethanol, flavonoids and tannins were present alongside alkaloids. Despite that, glycosides and saponins were absent. As for $M$. koenigii, when the plant is extracted by using $80 \%$ methanol, the result was similar to that $E$. elatior, the alkaloids, glycosides and saponins were present, while tannins and flavonoids were not detected in the extract. However, when extracted with $95 \%$ ethanol, M. koenigii contains flavonoids, tannins and saponins. Other constituents which is glycosides and alkaloids were absent in this extract (Table 2).

\section{Disc diffusion assay}

The extracts were tested against Candida albicans on SDA plates at the concentration of 400 $\mathrm{mg} / \mathrm{mL}$. Both plant's extracts using $95 \%$ ethanol has exhibit zone of inhibition of $8.17 \pm 0.29 \mathrm{~mm}$ and $8.33 \pm 0.29 \mathrm{~mm}$ for E. elatior and M. koenigii respectively (Table 3 ), whereas the methanol extracts for both plants do not show any zone of inhibition. The positive control also yield a zone of inhibition with the diameter of $20.33 \mathrm{~mm}$ while control negative do not show any activity (Fig. 1).

\section{Determination of MIC and MFC}

MIC determination was performed on

Table 1. The percentage of yield of the plant extracts with $80 \%$ methanol and $95 \%$ ethanol.

\begin{tabular}{lccc}
\hline Plants & $\begin{array}{c}\text { Crude } \\
\text { extracts }\end{array}$ & $\begin{array}{c}\text { Weight } \\
(\mathrm{g})\end{array}$ & $\begin{array}{c}\text { Percentage } \\
\text { of yield (\%) }\end{array}$ \\
\hline Etlingera elatior Jack. & 80\% methanol & 5.8 & 5.8 \\
& $95 \%$ ethanol & 12.5 & 12.5 \\
Murraya koenigii Spreng & $80 \%$ methanol & 5.2 & 5.2 \\
& $95 \%$ ethanol & 11.8 & 11.8 \\
\hline
\end{tabular}

Table 2. Zone of inhibition of $C$. albicans by the plant extracts

\begin{tabular}{lccc}
\hline Species & Plant part & Crude extract & Zone of inhibition $(\mathrm{mm})$ \\
\hline Etlingera elatior Jack. & Flower & 80\% Methanol & $\mathrm{NA}$ \\
& & $95 \%$ Ethanol & $8.17 \pm 0.29$ \\
Murraya koenigii Spreng. & Leaves & $80 \%$ Methanol & $\mathrm{NA}$ \\
& & $95 \%$ Ethanol & $8.33 \pm 0.29$ \\
Positive control (Nystatin 100mg) & & 20.33 \\
Negative control (10\% DMSO) & & $\mathrm{NA}$ \\
\hline
\end{tabular}

NA= No Activity 
microtiter plate by using microdilution broth assay starting with the concentration of $400 \mathrm{mg} /$ $\mathrm{mL}$ followed by $200 \mathrm{mg} / \mathrm{mL}, 100 \mathrm{mg} / \mathrm{mL}, 50 \mathrm{mg} /$ $\mathrm{mL}, 25 \mathrm{mg} / \mathrm{mL}, 12.5 \mathrm{mg} / \mathrm{ml}, 6.25 \mathrm{mg} / \mathrm{mL}, 3.125$ $\mathrm{mg} / \mathrm{mL}, 1.56 \mathrm{mg} / \mathrm{mL}$ and $0.78 \mathrm{mg} / \mathrm{mL}$. Only extracts that show an antifungal activity were chosen for determining MIC. Meanwhile, MFC was determined by streaking each concentration to observe the growth of $C$. albicans after incubation at $37^{\circ} \mathrm{C}$ for 24 hours. The plates that contain less than three colonies of $C$. albicans were determined (Fig. 2). Both results of MIC and MFC was compared to determine the better extract in inhibiting $C$. albicans. MIC was determined at

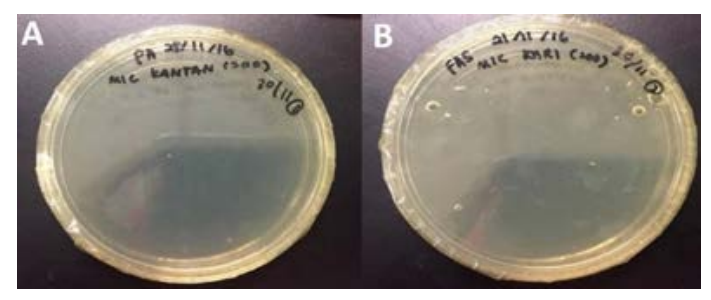

Fig. 2. The SDA plates that do not contain any $C$. albicans colony which is at $400 \mathrm{mg} / \mathrm{mL}$ and $200 \mathrm{mg} / \mathrm{ML}$ for E. elatior (A) and $M$. koenigii (B) respectively were determined as the MFC of the plant extracts.
$400 \mathrm{mg} / \mathrm{mL}$ for both extracts, as they were able to inhibit C.albicans. As for MFC, E. elatior was able to act as a fungicide against $C$.albicans at the concentration of $400 \mathrm{mg} / \mathrm{mL}$ while $M$. koenigii has a lower concentration $(200 \mathrm{mg} / \mathrm{mL}$ ) (Table 4).

\section{Checkerboard assay}

Based on this method, when the two extracts were combined using the concentration of $400 \mathrm{mg} / \mathrm{mL}$, the FIC yield was 1.0 (Table 5).

\section{DISCUSSION}

The study was to determine and explore the phytochemical constituents and antifungal activity of Etlingera elatior Jack. flowers and Murraya koenigii Spreng. leaves. The plant materials applied in extract preparation was based on the traditional used on the plants. In this study, the flower and leaves of E. elatior and $M$. koenigii were used respectively. At this stage, extraction conditions or solvent impurities is crucial in order to reduce interference from compounds that may co-extract with the target compounds, and to elude contamination of the extract, as well as to prevent decomposition of main metabolites or artefact formation ${ }^{19}$. Contamination with diseased

Table 3. The presence of different phytochemicals in E. elatior and M. koenigii ectracts extracted using $80 \%$ methanol and $95 \%$ ethanol

\begin{tabular}{lcccccc}
\hline Plants & Crude extract & Flavonoid & Alkaloid & Tannins & Glycosides Saponins \\
\hline Etlingera elatior Jack. & $80 \%$ Methanol & - & + & - & + & + \\
& $95 \%$ Ethanol & + & + & + & - & - \\
Murraya koenigii Spreng. & $80 \%$ Methanol & - & + & - & + & + \\
& $95 \%$ Ethanol & + & - & + & - & + \\
\hline
\end{tabular}

Table 4. MIC and MFC of both plant extracts were determined and compared.

\begin{tabular}{lcccc}
\hline Plant & Extract & $\begin{array}{c}\text { Concen. } \\
(\mathrm{mg} / \mathrm{mL})\end{array}$ & $\begin{array}{c}\mathrm{MIC} \\
(\mathrm{mg} / \mathrm{mL})\end{array}$ & $\begin{array}{c}\mathrm{MFC} \\
(\mathrm{mg} / \mathrm{mL})\end{array}$ \\
\hline Etlingera elatior Jack & $95 \%$ ethanol & 400 & 200 & 400 \\
Murraya koenigii Spreng & $95 \%$ ethanol & 400 & 200 & 200 \\
\hline
\end{tabular}

plant materials may lead to an unexpected formation of foreign products during the analysis due to alternation in the plant's metabolism or microbial synthesis in plants ${ }^{20}$.

Active compound from plant tissues can be extracted from either fresh or dried plant material. Dried plant materials was chosen
Table 5. FIC of the combined plant extracts when tested against $C$. albicans

FIC

Combined extracts of

E. elatior $(400 \mathrm{mg} / \mathrm{mL})$ and

M. koenigii $(400 \mathrm{mg} / \mathrm{mL})$
1.0 
in this study, because it was generally used by complementary and alternative medicine practitioners. The drying process is important to remove the water content from plants so that it can be stored. Fresh plant samples have to be dried immediately upon the collection to avoid spoilage of plant materials. The natural drying process includes sun-drying in which the plant materials were to be air-dried in barns or sheds. The time depends on temperature and humidity. Artificial drying by artificial driers that will reduce the drying time to several hours or minutes at a low temperature to avoid any chemical changes. The medicinal plant is commonly dried by warm-air drying method ${ }^{20,21}$.

Fresh plant materials have water property that may alter the solubility of following separation in liquid-liquid extraction. Prior to analysis, dehydrated plant materials can be kept for long time and metabolic plant components should be more stable, especially when used as an antimicrobial agent ${ }^{22}$. A study by Pham et al., (2015) stated that Helicteres hirsuta Lour leaves after being dried has low water activity which could be stored for a long time with minimum degradation ${ }^{23}$. Hence, dried plant materials were preferred instead of fresh.

In this study, Etlingera elatior Jack. flowers and Murraya koenigii Spreng. leaves extrcats were investigated for antifungal activity. The yield of the extracts varied between the solvent used. The results revealed that $95 \%$ ethanol was able to yield a higher percentage of extract for both plants used.

The presence of different complex chemical substances as secondary metabolites or phytochemicals, which accumulated in different parts of the plants provide medicinal properties and produce marked healing action on human body ${ }^{24}$. Phytochemical analysis of the Etlingera elatior Jack. and Murraya koenigii Spreng. crude extracts showed that only plants that were extracted using 95\% ethanol were able to extract out tannins. Tannins are a crucial phytochemical as it has antifungal properties that can work against Candida albicans ${ }^{25}$. "Tannin" is a group of polymeric phenolic substances that capable of tanning leather or precipitating gelatine from solution, a property known as acerbity and highly toxic towards filamentous fungi, yeasts, and bacteria ${ }^{26}$. The phytochemical content and the quality of plant extracts were highly influenced by the part of the plant and the process and the procedure of plant extraction as well as the different type of solvent used ${ }^{22}$. The difference of extraction procedure will affect the quality, quantity and secondary metabolites in the extracts which may be caused by the time of extraction, duration of extraction, polarity and nature of the solvent used. Phytochemical constituents of a plant's crude extracts be influenced by the environment of the plant material, the source, the particle size and moisture content ${ }^{22}$.

The result obtained in disc diffusion assay by using Kirby-Bauer Technique showed that the only plant extracts extracted by using $95 \%$ ethanol was able to produce a zone of inhibition. Meanwhile, when extracted with $80 \%$ methanol, the extracts failed to exhibit any zone of inhibition. This is due to the absence of the phytochemical constituent tannins in the extracts, thus, making it unable to kill the microorganism. For crude extracts obtained by extracting the plant by using $95 \%$ ethanol, Murraya koenigii was able to inhibit the growth of $C$. albicans greater than Etlingera elatior with a zone of inhibition of 8.33 $\pm 0.29 \mathrm{~mm}$ compared to $E$. elatior with only 8.17 $\pm 0.29 \mathrm{~mm}$. Positive control, Nystatin produces the largest diameter of a zone of inhibition which was $20.33 \mathrm{~mm}$ and negative control (10\% DMSO) do not exhibit any zone of inhibition. The disc diffusion assay was categorized it strength based on inhibition zones that is $\leq 9.5 \mathrm{~mm}$ is considered weak, 10 to $14.5 \mathrm{~mm}$ as moderate and $\geq 15 \mathrm{~mm}$ as strong ${ }^{27}$. Since the plant extracts have diameters $\leq 9.5 \mathrm{~mm}$, the antifungal activity were considered to be weak ${ }^{27}$.

For determining MIC, it was done on microtiter plate by using microdilution broth assay starting with the concentration of $400 \mathrm{mg} / \mathrm{mL}$ followed by $200 \mathrm{mg} / \mathrm{mL}, 100 \mathrm{mg} / \mathrm{mL}, 50 \mathrm{mg} / \mathrm{mL}$, $25 \mathrm{mg} / \mathrm{mL}, 12.5 \mathrm{mg} / \mathrm{ml}, 6.25 \mathrm{mg} / \mathrm{mL}, 3.125 \mathrm{mg} /$ $\mathrm{mL}, 1.56 \mathrm{mg} / \mathrm{mL}$ and $0.78 \mathrm{mg} / \mathrm{mL}$. After 24 hours being incubated, the microtiter plate was observed and the turbidity was recorded. It was observed that the MIC for both plant extracts was $200 \mathrm{mg} /$ $\mathrm{mL}$, suggesting that the capability of both plants to inhibit Candida albicans were similar. Despite that. MFC determination confirmed that $M$. koenigii was more powerful than $E$. elatior. This is because $M$. koenigii were able to act as fungicidal towards $C$. 
albicans at $200 \mathrm{mg} / \mathrm{mL}$ while $E$. elatior was only able at the concentration of $400 \mathrm{mg} / \mathrm{mL}$. Thus, less extract is needed for $M$. koenigii to inhibit Candida albicans.

As for determining the synergistic antifungal effects of $E$. elatior and $M$. koenigii, checkerboard assay were done with a similar method to determining MIC. It was found that the MIC of E. elatior in combination was $400 \mathrm{mg} / \mathrm{mL}$ and it was the same with $M$. koenigii. According to Gulam and Bhoj (2015), if $\sum F I C \leq 0.5$, there is synergy between the two plants and if the $\angle F I C \geq$ 4 , the synergy was considered to be antagonist ${ }^{23}$. However, the FIC in this study was 1.0, hence, it was considered to be indifferent towards $C$. albicans. So, the synergism can either be obtained or it does not affect the fungus ${ }^{28,29}$. This happened because synergism may decrease due to the incompatibility of phytochemical content from each of the plant or competitive inhibition at the site of action ${ }^{30}$.

\section{CONCLUSIONS}

Murraya koenigii Spreng. leaves and Etlingera elatior Jack. flowers could potentially be used individually or in combination as an antifungal agent against Candida albicans. Both plants extracts possess phytochemicals flavonoids, alkaloids, tannins, glycosides and saponins that might play important role in the antifungal activity.

\section{ACKNOWLEDGMENTS}

The authors would like to acknowledge Management \& Science University (MSU) for providing the facilities for this study.

\section{CONFLICT OF INTEREST}

The authors declare that there is no conflicts of interest.

\section{AUTHORS' CONTRIBUTION}

$\mathrm{OZ}$ and ZA design the study and supervised the implementation. AF performed data collection and analysis. AF and $\mathrm{OZ}$ interpret the data and prepare the draft of manuscript. All authors read and approved the manuscript.

\section{FUNDING}

This project was funded by MSU Seed Research Grant (SG-457-0518-HLS).

\section{ETHICS STATEMENT}

Permission to carry out this study was granted by the MSU Research Ethics Committee (Code :AE-MSU-015) of Management \& Science University (MSU).

\section{DATA AVAILABILITY}

Datasets during and/or analysed during the current study are available from the corresponding author upon reasonable request.

\section{REFERENCES}

1. Ong HC. Traditional Knowledge of Medicinal Plants among the Malay Villagers in Kampung Mak Kemas, Terengganu, Malaysia. Stud Ethno-Medicine. 2011.

2. Jiyauddin K, Zulhabri O, Aishah UAM, et al. Evaluation of Antioxidant and Antimicrobial Activity of Artocarpus altilis Against Human Pathogens. UK J Pharm Biosci. 2014;2(4):10-14. doi: 10.20510/ukjpb/2/i4/91110

3. Abuduli M, Aljunid S. Guest Editorial Role of Traditional and Complementary Medicine in Universal. Malaysian J Public Heal Med. 2011;11(2):1-5.

4. Ekor $\mathrm{M}$. The growing use of herbal medicines: Issues relating to adverse reactions and challenges in monitoring safety. Front Neurol. 2014;4:177. doi: 10.3389/fphar.2013.00177

5. Awad H, EL-Shahed KY, Aziz R, Sarmidi MR, El-Enshasy HA. Antibiotics as microbial secondary metabolites: Production and application. J Teknol. (Sci. Eng.) 2012. doi: 10.11113/jt.v59.1593

6. Selvam DA, $\mathrm{Ng} \mathrm{CH}$, Razik RM, Al-Dhalli S, Shaari $K$. Effects of extraction methods on antibacterial activity of centella asiatica leaves against pathogenic staphylococcus aureus and escherichia coli. Int J Med Toxicol Leg Med. 2019;22(1-2):172-178. doi: 10.5958/0974-4614.2019.00037.8

7. Krishnaiah D, Devi T, Bono A, Sarbatly R. Studies on phytochemical constituents of six Malaysian medicinal plants. J Med Plants Res. 2009.

8. Doel MA, Segrott J. Materializing complementary and alternative medicine: Aromatherapy, chiropractic, and Chinese herbal medicine in the UK. Geoforum. 2004;35(6):727. doi: 10.1016/j.geoforum.2004.02.004

9. Khaw S. The genus Etlingera (Zingiberaceae) in Peninsular Malaysia including a new species. Gard Bull Singapore. 2001.

10. Aziman N, Abdullah N, Mohd Noor Z, Zulkifli KS, Wan Kamarudin WSS. Phytochemical constituents and in vitro bioactivity of ethanolic aromatic herb extracts. Sains Malaysiana. 2012.

11. Abdelwahab SI, Zaman FQ, Mariod AA, Yaacob $\mathrm{M}$, Ahmed Abdelmageed AH, Khamis S. Chemical composition, antioxidant and antibacterial properties of the essential oils of Etlingera elatior and Cinnamomum pubescens Kochummen. J Sci Food Agric. 2010;90(15). doi: 10.1002/jsfa.4140

12. Trease GE, Evans WC. Pharmacognosy. $16^{\text {th }}$ ed. New York; 2009.

13. Mace ME. Histochemical Localization of Phenols in 
Healthy and Diseased Banana Roots. Physiol Plant. 1963;16(4):915-925. doi: 10.1111/j.1399-3054.1963. tb08367.x

14. Kokate C. Practical Pharmacognosy. $4^{\text {th }}$ editi. New Delhi: Vallabh Prakashan Publication; 1999.

15. Hammer KA, Carson CF, Riley T V. In-vitro activity of essential oils, in particular Melaleuca alternifolia (tea tree) oil and tea tree oil products, against Candida spp. J Antimicrob Chemother. 1998;42(5):591-595. doi: 10.1093/jac/42.5.591

16. Cockerill FR, Wikler MA, Alder J, et al. Methods for Dilution Antimicrobial Susceptibility Tests for Bacteria That Grow Aerobically. Clinical and Laboratory Standards Institute. 2012.

17. Kirby W, Bauer A, Sherris J, Turk M. Antibiotic susceptibility testing by standard single disk method. Am J Clin Pathol. 1966.

18. Gulam M, Bhoj R. Methods for determining Fractional Inhibitory Concentration (FIC). Published 2017. Accessed July 25, 2019.

19. Jones WP, Kinghorn AD. Extraction of plant secondary metabolites. Methods Mol Biol. 2012:341-366. doi: 10.1007/978-1-61779-624-1_13

20. Harborne JB. Phytochemical Methods: A Guide to Modern Techniques of Plant Analysis. Second Ed., Chapman and Hall, New York, USA. 1984.

21. Banu KS, Cathrine L. General Techniques Involved in Phytochemical Analysis. Int J Adv Res Chem Sci. 2015;2(4):25-32.

22. Ncube NS, Afolayan AJ, Okoh Al. Assessment techniques of antimicrobial properties of natural compounds of plant origin: Current methods and future trends. African J Biotechnol. 2008;7(12):17971806. doi: 10.5897/AJB07.613
23. Pham H, Nguyen V, Vuong $Q$, Bowyer $M$, Scarlett C. Effect of Extraction Solvents and Drying Methods on the Physicochemical and Antioxidant Properties of Helicteres hirsuta Lour. Leaves. Technologies. 2015;3(4):285-301. doi: 10.3390/technologies3040285

24. Bashir S, Erum A, Kausar R, Saleem U, Ruqia-Tulain $U$, Alamgeer. Antimicrobial activity of some ethnomedicinal plants used in Pakistan. Res Pharm. 2012;2(1):42-45.

25. Donatiello S. Tannin ( tannic acid) treatment of athlete's foot and other fungal infections. 1999:5-7.

26. Omojate GC, Enwa FO, Jewo AO, Eze CO. Mechanisms of Antimicrobial Actions of Phytochemicals against Enteric Pathogens - A Review. J Pharm Chem Biol Sci. 2014.

27. Hashim NM, Rahmani M, Ee GCL, et al. Antioxidant, antimicrobial and tyrosinase inhibitory activities of xanthones isolated from artocarpus obtusus F.M. Jarrett. Molecules. 2012;17(5):6071-6082. doi: 10.3390/molecules17056071

28. Sundaran, DV Faller E, Razik M. Synergistic antifungal activity of limonoids isolated from sky fruit ( swietenia ma crophylla king ) and limeberry ( triphasia trifolia (burm. f.) p. wilson ) seeds against selected fungal pathogens. J Manag Sci. 2017;15(1):2017.

29. Jiyauddin K, Samer AD, Darashhni T, et al. Comparison of Antibacterial Activity of Ocimum Tenuiflorum L . and Plectranthus Amboinicus ( Lour.) Spreng Against the Clinical Pathogens Staphylococcus Aureus, Pseudomonas. World J Pharm Res. 2015.

30. Ofokansi KC, Attama AA, Uzor PF, Ovri MO. Evaluation of the combined antimicrobial activity of the leaf extract of phyllantus muellerianus with ciprofloxacin. J Pharm Technol Drug Res. 2013;2(1):16. doi: 10.7243/2050-120X-2-16 